\title{
HANS JONAS: O PRINCÍPIO RESPONSABILIDADE, OS LIMITES DA PESQUISA (?) E AS NANOTECNOLOGIAS
}

\section{HANS JONAS: THE PRINCIPLE RESPONSABILITY, LIMITS OF RESEARCH (?) AND NANOTECHNOLOGIES}

\author{
${ }^{1}$ Patricia Santos Martins \\ ${ }^{2}$ Wilson Engelmann
}

\begin{abstract}
RESUMO
O estudo pretende realizar a leitura do princípio responsabilidade e o novo modelo ético narrado por Hans Jones ao contexto das nanotecnologias. Estudar o contexto histórico de desenvolvimento político e econômico e as inter-relações com o desenvolvimento tecnológico, visitando as transformações do homo sapiens homo faber homo tecnologicus. Verificar se, exploração em escala nano, compreendida na bilionésima parte de metro, possui elementos que possam indicar eventuais danos que comprometam ou ofereçam riscos ao exercício de direitos para as futuras gerações. Neste sentido, pretende encontrar pontos de convergência entre a gestão dos possíveis riscos decorrentes das nanotecnologias e o novo modelo ético proposto por Hans Jonas em sua obra O princípio responsabilidade ensaio de uma ética para a civilização tecnológica. $\mathrm{O}$ estudo lança bases na obra citada como fundamento teórico para o estudo, bem como se fundamenta na noção de risco proposta por Niklas Luhmann, e utiliza o método de consulta bibliográfica a estas obras bem como artigos publicados que envolvam os temas abordados.
\end{abstract}

Palavras-chave: Princípio responsabilidade, Ética, Nanotecnologias

\begin{abstract}
The study intends to carry out the reading of the responsibility principle and the new ethical model narrated by Hans Jones to nanotechnology context. Study the historical context of political and economic development and the interrelations with technological development, visiting the transformation of homo sapiens - homo faber - homo tecnologicus. Check if operating at the nanoscale, comprised in the billionth of meter, has elements that may indicate possible damage that might compromise or offer risks to the exercise of rights for future generations. Therefore, we intend to find points of convergence between the management of the potential risks of nanotechnologies and the new ethical model proposed by Hans Jonas in his work "The principle responsibility test an ethics for technological civilization". The study sheds bases in the work cited as theoretical foundation for the study and is based on the notion of risk proposed by Niklas Luhmann, and uses the method of literature refers to these works as well as published articles involving the topics covered.
\end{abstract}

Keywords: Principle responsibility, Ethics, Nanotechnology

\footnotetext{
${ }^{1}$ Graduada em Direito pela Faculdade Católica Dom Orione - FACDO, Araguaína - TO (Brasil).

E-mail: patricia.mart@hotmail.com

${ }^{2}$ Doutor em Direito pela Universidade do Vale do Rio dos Sinos - UNISINOS, São Leopoldo - RS (Brasil) Professor da Universidade do Vale do Rio dos Sinos - UNISINOS, São Leopoldo - RS (Brasil).

E-mail: wengelmann@unisinos.br
} 


\section{INTRODUÇÃO}

O presente estudo é uma reflexão sobre aspectos éticos que envolvem o desenvolvimento humano e tecnológico, suas descobertas e limites éticos que devem ser respeitados e parte da leitura da obra de Hans Jonas "O princípio responsabilidade: ensaio de uma ética para a civilização tecnológica". Além disso, se propõe a visitar outros conceitos visando encontrar um elo entre a histórica superação do homem pelo homem (homo sapiens - homo faber

- homo tecnologicus), as descobertas tecnológicas (biotecnológicas e nanotecnolgicas). Também se pretende verificar as questões de desenvolvimento político e econômico e as inter-relações com o desenvolvimento tecnológico. Por fim, os possíveis limites à exploração tecnológica e nanotecnológica (tendo em vista a ausência de marcos regulatórios face à dignidade humana), buscando verificar o conteúdo ético orientador das tomadas de decisões.

Especificamente o estudo possui duas iniciativas: refletir sobre as interferências humanas no meio ambiente e em sua própria existência (através do desenvolvimento de tecnologias) e divulgar as ideias de Hans Jonas a respeito de um novo modelo ético que culmina da noção de responsabilidade, apresentando-se como possível limitador da conduta humana no avanço técnocientífico. Correto afirmar que a leitura deseja evidenciar que há um limite a ser respeitado, ainda que não se tenha uma lei específica para determiná-lo diante do desenvolvimento tecnológico/nanotecnológico.

Além disso, busca evidenciar que avanços nano-tecno-científico também trazem riscos, não somente benefício, motivo que leva a introduzir, no presente estudo, aspectos que envolvem os riscos das novas tecnologias e nanotecnologias em relação à saúde e meio ambiente e também algumas noções a respeito do desenvolvimento sustentável, para isto, busca-se apoio em autores que tratam da noção de risco e nanotecnologias.

Esta é a razão pela qual se pergunta: é correto aplicar à realidade atual do desenvolvimento humano e (nano)tecnológico um conceito ético clássico? A perspectiva do novo modelo ético proposto por Hans Jonas apresenta-se adequado para o novo context (nano)tecnológico?

Cientes de que o desenvolvimento tecnológico no qual o homem empregou esforços ao longo da história, é um caminho sem volta, não se poderá retornar ao status quo do desenvolvimento, todavia, a proposta é verificar que gerir o conhecimento colocando-o a serviço 
do homem surge como alternativa sustentável, principalmente aplicando-se os recursos econômicos derivados deste desenvolvimento a fim de proporcionar igualdade e sustentabilidade.

\title{
1 O POTENCIAL CRIATIVO DO HOMEM E O DESENVOLVIMENTO TECNOLÓGICO
}

Ao iniciar o tema proposto, necessário retroceder o olhar para o comportamento humano na natureza e em relação a ela. As alterações provocadas pelo homem, inicialmente como ser integrante do meio, cujo objetivo era a subsistência da espécie até a necessidade de domínio da natureza, que segundo Férriz, Férriz e Ribeiro (2008, p.4) demonstra que "o êxito de atingir o máximo domínio sobre as coisas e sobre os próprios homens é visto como a realização máxima do destino do homem: 'homo faber mais que homo sapiens'...como se essa fosse a missão da humanidade".

A natureza passa a ser alvo das transformações por ele promovidas e destinatária de suas consequências; Férriz, Férriz e Ribeiro (2008, p.2) ponderam dizendo:

\begin{abstract}
A tremenda vulnerabilidade da natureza submetida à intervenção tecnológica do homem mostra uma situação inusitada, pois nada menos que toda a biosfera do planeta torna-se passível de ser alterada o que torna imprescindível considerar, que não somente o bem humano deve ser almejado, mas também o de toda a natureza extra humana.
\end{abstract}

Razão pela qual, ao referir sobre a obra humana 'da cidade' Hans Jones indica um significado para além da intervenção humana na natureza, mas justifica que, inicialmente, o agir interventor dentro de uma perspectiva humana, sobre o meio ambiente, de fonte inesgotável de bens, demonstrava o quão imutável representava a ordem cósmica, visão que possibilitou a 'construção das cidades' e seu objetivo sempre foi obter contraprestação, a compensação recíproca (2006, p.33).

Esta atividade humana é vista como forma de garantir sua autonomia e liberdade, nas palavras de Barreto: “o acesso ao conhecimento irá tornar o homem livre, pois será o ato mais revolucionário de toda a cultura humana. A liberdade e o seu exercício irão compor-se no âmbito do conhecimento humano e, em virtude dele, os direitos humanos terão como condição primeira de sua objetivação as possibilidades da ciência e da técnica” (2013, p.27). 
A capacidade inventiva do homem face aos danos que sua interferência pode produzir torna necessário que se estabeleçam limites. Primeiramente, "todo bem ou todo mal que sua capacidade inventiva pudesse proporcionar situava-se sempre dentro dos limites de ação do ser humano, não afetando a natureza das coisas extra-humanas" (SIQUEIRA, 1998, p.6), porém posteriormente as interferências alcançam áreas da biologia, por exemplo, como a manipulação genética, e na física a manipulação atômica.

A necessidade de interferir com o objetivo de alcançar uma compensação, logo se transforma em choque, quando o homem percebe pelos danos provocados, que o objeto de seu domínio, a natureza, é vulnerável. Neste sentido, nas palavras de Jones (2006. P.39) “uma vulnerabilidade que jamais fora pressentida antes de que ela se desse a conhecer pelos danos já produzidos". Percebida a vulnerabilidade da natureza e que não se trata de 'fonte inesgotável de bens' passíveis de transformações, o homem passa a ter o dever de proteger, inclusive sua conduta. Nas palavras de Hans Jonas:

A presença do homem no mundo era um dado primário e indiscutível de onde partia toda a ideia do dever referente à conduta humana: agora, ela própria tornou-se um objeto de dever - isto é, o dever de proteger a premissa básica de todo o dever, ou seja, precisamente a presença de meros candidatos a um universo moral no mundo físico do futuro; isso significa entre outras coisas, conservar este mundo físico de modo que as condições para uma tal presença permaneçam intactas; e isto significa proteger a sua vulnerabilidade diante de uma ameaça dessas condições (2006, p.45).

Assim, a partir da percepção da vulnerabilidade e do reconhecimento do dever de proteção, inclusive quanto à própria conduta, não se está mais diante de um homem que age para subsistir ou obter compensações, mas diante de uma ética, ainda que "o alcance das prescrições éticas reduziase ao âmbito da relação com o próximo no momento presente” (SIQUEIRA, 1998, p.7), contudo, atualmente "enfrentamos o desafio de colaborar como estranhos morais em um mundo secular privado de essência moral canônica e orientadora” (ENGELHARDT JR, 1998, p.

O que inicialmente representava uma ação do homem em suas investidas no mar, céu e terra, sem provocar algum dano, chega, na modernidade, conforme Férriz, Férriz e Robeiro, com a constatação de que houve a "emancipação da ciência” (FÉRRIZ, FÉRRIZ E RIBEIRO, 2008, p.3) a humanidade "aprendera como era o universo, descobriu que não necessitava de tutores para 
pensar" (2008, p.3). Na pós modernidade, se transforma em razão da visão do homem como um ser que se move em razão de sua virtude e sabedoria, segundo os princípios da honra, justiça e caridade (FÉRRIZ, FÉRRIZ E RIBEIRO, 2008, p.3).

$\mathrm{O}$ ápice das descobertas nas áreas da química, física e matemática, para Férriz, Férriz e Ribeiro, culminou com a Revolução Industrial dando início ao período em que as máquinas substituíram a força humana (2008, p.3), resultando em questões atinentes a este desenvolvimento, como o impacto ambiental e social devido à poluição, exploração das fontes energéticas, criação de grandes áreas agrícolas, crescente urbanização, acumulação de população em subúrbios, aumento das desigualdades, novos problemas de saúde pública, etc.(FÉRRIZ, FÉRRIZ E RIBEIRO, 2008, p.3).

Adentrando a pós-modernidade, com o avanço da exploração tecnológica, o avanço da ciência e a manipulação do átomo pelo homem (bomba atômica e estabelecimento do código genético - DNA, etc) se estabelece um período de superioridade do homem, maravilhado pelas próprias invenções (computador, telecomunicações, redes de transporte, internet, clonagem, missões espaciais) que lhe "permitiram suspeitar que já nada seja impossível à humanidade”(FÉRRIZ, FÉRRIZ E RIBEIRO, 2008, p.4).

Não se pode olvidar que o avanço tecnológico e a interferência humana na natureza não se apresenta apenas em seu aspecto negativo; ao tratar deste tema, Ferrer comenta:

\footnotetext{
De hecho, a lo largo de la historia há sido la tecnologia la que há determinado los modelos sociales imperantes em cada momento. La noción de sociedade es evidentemente polimórfica pero lo que es essencial para que podamos hablar de sociedade es la existência de interaciones entre indivíduos. Sin interaciones no hay sociedade y sin comunicación no hay interaciones. De este modo, las tecnologias de transporte y comunicación han determinado la amplitude y estrutura de las sucessivas sociedades $(2014$, p.12)
}

Portanto, impossível negar que o avanço científico e tecnológico, proporcionou “conquistas e mais-valias para o homem", importa refletir que a "natureza não foi convocada a responder às solicitações humanas" esgotando-se progressivamente, pontuando o século XX como o ápice do sofrimento da Natureza (FÉRRIZ, FÉRRIZ E RIBEIRO, 2008, p.4).

Supiot ao falar do desenvolvimento do século XX refere, evidenciando um aspecto negativo do desenvolvimento: 
Os primitivos é que eram tratados como coisas a explorar ou a exterminar segundo seu grau de utilidade ou incômodo. A exploração das classes trabalhadoras europeias desenvolvia-se, ao contrário, sob a égide dos princípios de igualdade e de liberdade contratual que, longe de negar sua humanidade, deveriam, supostamente, permitir sua perfeita realização $(2014$, p.11).

Além disso, as transformações provocadas pelos "horrores da primeira metade do século XX procedia da síntese de dois fenômenos antes distintos: os 'primitivos não eram mais os únicos olhados e tratados como coisas, mas os povos 'civilizados' também o eram; e a gestão industrial dos homens não foi mais limitada às usinas, mas afirmou-se como princípio geral de governo, em tempos de paz como em tempos de guerra" (SUPIOT, 2014, p.11).

Também importante relembrar o "slogan sob a égide do qual foi aberta a Exposição Universal de Chicago em 1933 - 'A ciência encontra, a indústria aplica, o homem se adapta' esta ideologia de gestão científica do humano não foi o apanágio dos países totalitários" (SUPIOT, 2014, p.14), evidencia do domínio do homem pelo homem através do avanço científico e tecnológico (para Supiot: gestão humana industrial).

As descobertas científicas também permitiram que "sociedades humanas fossem vistas como coisas, como vastos organismos, cujo funcionamento obedece às leis internas de organização" (SUPIOT, 2014, p. 16-17). Assim, o poder criativo humano (evidente pela evolução do desenvolvimento) leva a condição de que se estabeleça um parâmetro ético capaz de representar um limite ou um parâmetro delineador do agir humano. Neste sentido, Hans Jonas propõe uma nova ética em que se fundamenta a tese por ele apresentada na obra $\mathrm{O}$ princípio responsabilidade: Ensaio de uma ética para a civilização tecnológica, que o presente estudo busca divulgar.

\section{A ÉTICA PROPOSTA POR HANS JONAS E A SUSTENTABILIDADE TECNOLÓGICA}

As alterações provocadas pelo homem e a tendência de estar constantemente conquistando novos horizontes, em diversos campos da ciência, proporciona outros olhares sobre a transformação: homo sapiens - homo faber. Ferrer ao tratar da sustentabilidade tecnológica, explica o que denomina de homo tecnologicus, segundo o autor, de toda a natureza, o homem é o produto mais paradoxal que existe; o mundo atual nada mais é do que um produto da razão humana, 
e a combinação da tecnologia e da razão que dá lugar a tecnologia, e tudo o que rodeia o homem não pode ser mais artificial, ou seja, um produto da arte, neste sentido se estabelece o paradoxo: o ser humano é um ser "contra-natura" ou "anti-natura" convertendo-se definitivamente em um homo tecnologicus (2014, p.11).

Ferrer considera inquestionável que se deva reconhecer que a tecnologia é determinante para fazer entender o comportamento atual e também futuro da espécie humana. Igualmente comenta sobre a capacidade de captar e gerir o conhecimento do homo sapiens somada à habilidade de criar artefatos do homo faber cede lugar a uma nova dimensão da natureza humana. De sorte que hoje, desenvolve sua vida em função dos utensílios que desenvolve e constrói, fazendo-o de forma coletiva, ou seja, trata-se de uma sociedade tecnológica ou uma "tecno- sociedad" (2014, p.12).

Assim, as ponderações de Ferrer, não estão equidistantes do contexto apontado por Hans Jonas, ao estudar o imperativo categórico Kantiano e propor um novo imperativo categórico expondo seus fundamentos, Jonas inicia relembrando:

O imperativo categórico de Kant dizia: 'Aja de modo que tu também possas querer que tua máxima se torne lei geral'. Aqui o que tu possas invocado é aquele da razão e de sua concordância consigo mesma: a partir da suposição da existência de uma sociedade de atores humanos (seres racionais em ação), a ação deve existir de modo que possa ser concebida, sem contradição, como exercício geral da comunidade (2006, p.47)

Esta é a razão pela qual Jonas pondera que o imperativo categórico apresentado, poderia estar adequado à ética de então, era voltado para o indivíduo e possuía um critério momentâneo(JONAS, 2006, p.48). Mas o progresso da ciência e a possibilidade da interferência do homem interromper a existência da sua própria espécie, impunha um novo modo de pensar a ética, e, portanto, um novo imperativo categórico (2006, p.47).

O imperativo categórico de Kant, parte da reciprocidade entre os homens, sem considerar os bens extra-humanos, já, para Jonas, o dever para com o futuro deve ser considerado a partir de uma nova ética, que leve em conta aquilo que ainda não existe, desapegando-se da ideia de reciprocidade segundo a qual "o meu dever é a imagem refletida do dever alheio, que por seu turno é visto como imagem e semelhança do meu próprio dever, de modo que, uma vez estabelecidos certos direitos do outro, também se estabelece o meu dever de respeitá-los e, se possível promove-los" (JONAS, 2006, p.89) e o dever diante da posteridade significa "uma 
responsabilidade em relação à humanidade futura" (JONAS, 2006, p.90) uma vez que se deve “supor a continuidade da existência" (JONAS, 2006, p.90). Para Jonas, a ética existe para ordenar as ações humanas e, regular seu poder de agir, a existência de uma ética será “tanto mais necessária, portanto, quanto maiores forem os poderes do agir que ela tem de regular" (JONAS, 2006, p.65-66).

Hans Jonas formula assim um novo imperativo dizendo: "aja de modo a que os efeitos da tua ação sejam compatíveis com a permanência de uma autêntica vida humana sobre a Terra" ou "Aja de modo a que os efeitos da tua ação não sejam destrutivos para possibilidade futura de uma tal vida" (2006, p.47-48).

Uma das reflexões basilares do novo imperativo de Jonas é "o elemento da aposta, no agir humano" (JONAS, 2006, p.48). Ou seja, se o agir é inconsciente importa identificar o quanto uma consciência ética poderá tolerar de inconsciência, em outras palavras, o quanto se pode comprometer conscientemente ou colocar em risco conscientemente os interesses alheios. Sobretudo, porque nunca haverá uma razão que justifique apostar ou perder tudo, porém moralmente justificável, quando para tentar salvar o inalienável, correr o risco de perder tudo na tentativa (JONAS, 2006, p.48).

Assim, a "aposta" de que não se deve incluir a totalidade dos interesses alheios é relativa (2006, p.84-85). Neste sentido, considera que, na civilização técnica, o primeiro dever do comportamento coletivo humano é para com o futuro da humanidade e da natureza, principalmente em razão do elevado potencial destrutivo que a própria civilização técnica possui (2006, p.229). Justifica-se, assim, segundo Jonas "quando a luta pela existência frequentemente impõe a escolha entre o homem e a natureza, o homem, de fato, vem em primeiro lugar" (2006, p.229).

As ponderações contidas nos dizeres de Jonas ao falar do "elemento da aposta" significa dizer que há um reconhecimento de que decisões, tomadas com objetivo de beneficiar ou manter a preservação da espécie humana e o meio ambiente, possam acarretar danos. Estas decisões, em se tratando de desenvolvimento tecnologicamente sustentável, nas palavras de Ferrer representam o significado de sustentabilidade, qual seja: "La sustenibilidad no es outra cosa que um processo mediante el que se persigue construir uma sociedade global capaz de perpetuarse indefinidamente 
em el tempo em condiciones que aseguren la dignidade humana" (2014, p.3). Ou seja, há um objetivo a ser perseguido, o de se buscar a sustentabilidade através de decisões cujo elemento da aposta possa ser minimamente determinável no que refere ao comprometimento de direitos e bens jurídicos das gerações futuras; o limite, portanto é a dignidade humana.

Logo, para Ferrer, desenvolvimento sustentável é aquele que pode satisfazer as necessidades do presente, sem comprometer a capacidade para que as futuras gerações possam satisfazer suas próprias necessidades (2014, p.4). Isto inclui percepções econômicas e de gestão de recursos que possam assegurar um grau de justiça capaz de demonstrar o quanto as gerações presentes estão comprometidas com as possibilidades outorgadas às gerações futuras de um mundo mais habitável(FERRER, 2014, p.4).

Dentro da perspectiva de uma sociedade tecnológica, na expressão de Ferrer "tecnosociedad", cumpre lembrar que, historicamente a tecnologia é que tem determinado os modelos sociais de cada período e a noção de sociedade já induz a pensar no quão essencial para a sociedade são as interações entre os indivíduos. Também refletidas nos modelos políticos- econômicos determinantes na formação dos diversos modelos sociais. Logo, sem os avanços tecnológicos não haveria sociedade, de sorte que pode se dizer, que as tecnologias participam na determinação das características e estrutura das sociedades (2014, p.12).

Por isto é correto afirmar que, ao pensar um novo modelo ético e um novo imperativo, tanto Hans Jonas como Ferrer, ao fazerem suas considerações sobre sustentabilidade, defendem que, se a sustentabilidade pretende a construção de um modelo viável não se pode ignorar que o fator tecnológico será também determinante de como esta sociedade será.

Em todas as áreas ou dimensões (ambiental, tecnológica, econômica, etc) o fator decisivo será a adequada gestão do conhecimento, pois não existem possibilidades de "voltar atrás", o "voltar atrás" no desenvolvimento é incompatível com a condição humana, logo, a solução deverá vir através da ciência, como por exemplo, novos modelos energéticos não poluentes, produção sem resíduos ou gerindo os possíveis efeitos negativos, gestão de riscos (FERRER, 2014, p.14).

Significa também dizer que o homem deve colocar a tecnologia a seu favor, a seu serviço, para ajudar a natureza e como o homem é integrante dela, auxiliá-lo a reencontrar seu equilíbrio; ou que a prosperidade econômica deva ser inclusiva para que se possa falar em desenvolvimento sustentável (FERRER, 2014, p.14). 


\section{NANOTECNOLOGIAS: OS RISCOS E A ÉTICA SEGUNDO HANS JONAS}

Considerando o comportamento do homem e seu potencial criativo na exploração tecnológica, importa dar luz ao avanço e descobertas em escala nano. As nanotecnologias com sua natureza transdisciplinar, começam a ser objeto de discussão em diversas áreas do conhecimento. Razão pela qual ao adentrar este tópico, relevante conceituá-las e contextualizálas.

O físico norte-americano Richard Feynman é considerado o profeta da nanotecnociência, pois, em sua palestra "There is plenty of room at the bottom" ("Há mais espaços lá embaixo"), realizada no encontro anual da Sociedade Americana de Física do Instituto de Tecnologia da Califórnia, em 29 de dezembro de 1959, abordou praticamente todos os conceitos importantes da nanotecnociência, embora não a tenha nominado desta forma (BORGES; GOMES; ENGELMANN; 2014, p.5). Somente nos anos 80, o cientista Eric Drexler foi responsável por divulgar o termo nanotecnologia, ao referir-se "à construção de máquinas tão pequenas que teriam escala molecular com poucos nanômetros de tamanho" (BORGES; GOMES; ENGELMANN; 2014, p.5).

Assim, falar de nanotecnologias significa dizer do conjunto de diversas técnicas que possibilitam a manipulação da matéria em escala que vai de 1 a 100 nanômetros, ou equivalente a uma bilionésima parte do metro. Segundo Hohendorff e Engelmann, "as nanotecnologias são um conjunto de técnicas multidisciplinares que permitem o domínio de partículas com dimensões extremamente pequenas que exibem propriedades mecânicas, óticas, magnéticas e químicas completamente novas" (2014, p.22).

O tamanho adotado é equivalente a aproximadamente 100 mil vezes menor do que um fio de cabelo, 30 mil vezes menor do que um dos fios de uma teia de aranha ou, ainda, 700 vezes menor que um glóbulo vermelho (BORGES; GOMES; ENGELMANN, 2014, p.6-7). Presentes nas mais diversas áreas como em têxteis, fármacos, alimentos, cosméticos dentre outros, impulsiona também áreas como a economia, segundo Nogueira:

$\mathrm{O}$ avanço da nanotecnologia vem impulsionando o mercado mundial e potencializando o consumo de materiais, produtos e processos voltados para essa área. Tal fato é verificado através do uso de nanoprodutos em diferentes segmentos como alimentício, eletrônico, farmacêutico, biotecnológico, cosmético, médico-hospitalar, agrícola, entre outros (2013, p.60). 
As promessas são muitas e representam um encontro de potenciais benefícios e probabilidades de riscos, que, derivados da exploração nanotecnológica, possuem por destinatários o homem e o meio ambiente principalmente em face das reações físico-químicas diversas que a escala nano proporciona, como por exemplo, maior condutividade elétrica e consequentemente maior interação com o meio ambiente e o corpo humano (Hohendorff, ENGELMANN, 2014).

É possível dizer então, que as nanotecnologias representam a superação do homem pelo homem, em outras palavras, a capacidade de captar e gerir o conhecimento acerca da natureza, transformou o "homo sapiens" em "homo faber" com sua condição de criar artefatos úteis à sua sobrevivência, avançando para uma nova dimensão da existência humana, todavia, este homem, ao desenvolver sua vida em torno das ferramentas que projeta e constrói e, se desenvolve coletivamente, em uma tecno-sociedade, atinge o status de "homo tecnologicus"(FERRER, 2014, p.12).

No tocante às nanotecnologias, pesquisas apontam para possíveis riscos, Hohendorff e Engelmann, relatam que estudos feitos em plantas de soja, submetidas a um solo com materiais nanofaturados apresentam biodisponibilidade aos nanomateriais resultando diretamente em alteração da capacidade de produção (2014, p.79), razão pela qual, segundo os autores, “a preocupação tende a potencializar-se considerando as propriedades únicas dos nanomateriais e ambiguidade na sua transformação, reatividade e toxicidade" (2014, p.81).

Neste sentido, importa que sejam estabelecidos limites na exploração em escala nano, Engelmann afirma que "a nanotecnociência deverá inspirar-se nos limites humanamente construídos a partir da experiência, para avaliar os benefícios e riscos dos resultados produzidos" (2010, p.262), principalmente se for considerado o contexto legislativo atual de ausência de marcos regulatórios específicos, pois "a possibilidade de se investigar e aproveitar as coisas projetadas em escalas não visíveis microscopicamente" pode causar danos irreparáveis ao ser humano (e a sua dignidade) no futuro (ENGELMANN, 2009, p.320).

Assim, importa ressaltar a relevância do princípio da precaução, que exige a tomada de decisões em momentos fundamentais da pesquisa, ou seja, no seu início e na identificação do estágio onde se deve parar para avaliação (ENGELMANN, 2011, p.417). Por isto: 
[...] a escolha de quando se deve encerrar um experimento não é guiada por convenções arbitrárias não-racionais ou por interesses oportunísticos em acumular capital simbólico. [...] Que a decisão, a certeza de um procedimento experimental, a confiança em uma peça de aparelhagem ou o comprometimento com uma estratégia de modelização não possam ser formalizados ou dispostos em um esquema de um sistema dedutivo rígido, isto não diminui a sua importância na conclusão de experimentos e na produção de conhecimento. Chegar a uma decisão é um processo coletivo de consenso para a ação, mas ele não é por isso reduzido a uma negociação oportunística. (LENOIR, 2004, p. 54).

Engelmann complementa dizendo que a precaução deve indicar o caminho que as pesquisas em escala nano deve tomar; não guiando-se apenas para atender os apelos econômicos que são atraentes, mas avaliar, com mesmo grau de interesse, todas as possibilidades de situações de risco e perigo para o gênero humano (2011, p.418).

Consequentemente tal se dará, através da construção de formulas que integrem obrigatoriamente uma premissa ética, alicerçada no direito fundamental ao respeito à precaução, entendida como o cálculo, avaliação e projeção das consequências da exploração das nanotecnologias (ENGELMANN, 2011, p.418), ou seja, a gestão de riscos.

A gestão de riscos apresenta-se como ferramenta capaz de evitar prejuízos futuros, para Luhmann "o risco consiste nas consequências indesejadas e danos futuros decorrentes dos processos de tomadas de decisão (de um determinado sistema) havendo certa possibilidade de controle, e vincula-se às decisões tomadas no presente" (1992, p.65).

A tomada de decisões necessariamente coloca o homem em dois âmbitos que merecem ser foco de exame: participante do risco como portador de decisões ou como afetado por estas decisões (LUHMANN, 1992, p.45). Logo, estabelecer limites éticos nas pesquisas representa mais que adotar uma conduta precaucional, à luz do princípio responsabilidade defendido por Hans Jones, representa uma conduta baseada em uma nova ética, capaz de orientar as tomadas de decisões cujo risco de comprometer bens jurídicos ou direitos das gerações futuras esteja em jogo (JONAS, 2006, p.84). Ou um princípio ético que "proíbe certos 'experimentos' de que a tecnologia se tornou capaz" (JONAS, 2006, p.86), um princípio ético fundamental que impede que a essência ou existência do homem seja objeto de 'aposta no agir' (2006, p.85).

Este novo princípio ético descrito por Hans Jonas proíbe que na tomada de decisões se coloque em risco elementos que possibilitem a manutenção da espécie humana, noutras palavras “proíbe a aposta do tudo ou nada nas questões da humanidade” (2006, p.87), embora não sejamos 
responsáveis pelos homens futuros, temos responsabilidade pela "ideia do homem, cujo modo de ser exige a presença da sua corporificação no mundo" (JONAS, 2006, p.94).

Pode se dizer que a nova ética proposta por Jonas impõe ao homem e seu poder criativo e interventor na natureza, um limite, qual seja, a dignidade humana, que no cenário legislativo brasileiro foi "expressamente guindada à condição de fundamento da República Federativa do Brasil" (SARLET, 2014, p.62), ao ser elencada dentre os princípios e objetivos fundamentais, na Constituição Federa de 1988.

A dignidade humana, que segundo Barreto, "deita suas raízes, principalmente, no pensamento de Immanuel Kant" (2013, p.70), cujo núcleo da ideia kantiana da dignidade humana está intimamente ligado à liberdade e autonomia, culminando no conceito de dignidade que se expressa da seguinte forma: "a faculdade que tem a pessoa de estabelecer leis universais de comportamento as quais ela própria deve submeter-se" (BARRETO, 2013, p.72). Nas palavras de Barreto "o conteúdo do princípio da dignidade humana pode desdobrar-se em duas máximas: não tratar a pessoa humana como simples meio e assegurar as necessidades vitais da pessoa humana" (2013, p.74).

Todavia o Barreto também comenta da insuficiência da teoria clássica da responsabilidade diante da realidade tecnocientífica, mostrando a relevância de se vislumbrar a responsabilidade sob novos padrões éticos. Barreto assim esclarece: "as questões éticas na contemporaneidade transcendem o espaço restrito das relações inter-individuais, pois em virtude da tecnociência refletem os problemas encontrados no âmbito da ecologia, da natureza humana e do futuro da espécie humana" (2013, p.92).

Também refere que "a inquietação provocada pela aplicação de técnicas com efeitos contraditórios fez com que se procurasse um equacionamento ético que servisse na regulação dessas novas relações sociais" (BARRETO, 2013, p.92).

As nanotecnologias representam riscos para o homem e o meio ambiente, conforme já descrito pesquisas apontam para incertezas quanto aos seus efeitos. Razão pela qual, torna-se necessário inserir a gestão de riscos no contexto nanotecnológico, considerando-se a viabilidade de implementação de ferramentas que facilitem e evidenciem a tomada de decisões na gestão de riscos, ainda que não se tenha um marco regulatório especifico. 
Ademais, se impõe um repensar ético cuja teoria de Hans Jonas aparenta ser a mais adequada, pois tem por objetivo a preservação da humanidade, outorgando possibilidade de viabilizar condições para que as futuras gerações possam gerir os bens naturais em prol de si, ou seja, que os avanços tecnológicos do presente, estejam a serviço do homem, em sua tomada de decisões, baseada em uma ética que lhe garanta evitar prejuízos para as gerações futuras. Através do desenvolvimento sustentável e da aplicação das novas descobertas tecnológicas possibilitar que as gerações futuras sejam viáveis.

\section{CONCLUSÃO}

Ao finalizar o estudo, se pode constatar que a ação humana ao longo da história, provocou interferências (e até mesmo colocou em risco) o meio ambiente e a própria manutenção da existência humana, pois desenvolveu tecnologias que provocam riscos e comprometem a própria existência humana sobre a terra (manipulação do átomo - bomba atômica), e recentemente conquistou a escala nano, empregando esforços no desenvolvimento e aplicação de nanotecnologias em inúmeros produtos sem ter segurança quanto aos riscos (consumo em alimentos, têxteis, agrotóxicos e cosméticos - ou seja, consumo humano direto e indireto).

Além disso, se pode perceber que o avanço científico e as alterações políticas e econômicas caminharam ao longo da história, produzindo inter-relações, que em determinados períodos, o desenvolvimento tecnológico conquistado pelo homem, voltou-se contra a própria espécie, por exemplo, no auge dos regimes políticos ditatoriais, com a gestão humana industrializada, que trataram determinados grupos sociais como coisas ou organismos, conforme sua utilidade ou inutilidade para o sistema político e econômico daquela época.

Igualmente, se identifica que nem todo o avanço tecnológico traz apenas benefícios, mas carrega em seu bojo, uma probabilidade de efeitos negativos, pelos riscos tecnológicos, pelo mau uso da tecnologia ou ainda, por danos futuros. Por isto, a presente leitura se propôs e acredita ter alcançado o objetivo de demonstrar, que todo o avanço deriva, ao fim ao cabo, da transformação do homo sapiens - faber - tecnologicus, e que, somente a gestão tecnológica e dos bens com o intuito de gerir os riscos e minimizar as desigualdades sociais é que proporcionará, segundo a tese defendida por Hans Jonas, a viabilidade da espécie humana na Terra. 
As tomadas de decisões, portanto, não podem colocar em risco a sustentabilidade da vida e meio ambiente, nem comprometer bens jurídicos ou direitos das gerações futuras. Ainda que esta conduta humana seja contraditória - de conquistas e prejuízos - deve ser orientada por uma ética que permita a outorga de possibilidades de viabilidade e de manutenção do meio ambiente e do homem para o futuro, ou seja, é preciso que o homem utilize a tecnologia a seu favor desenvolvendo mecanismos de sustentabilidade como energia limpa, gerenciar os excedentes de produção, entre outras iniciativa.

Dentro desta perspectiva de sustentabilidade, se faz uma reflexão sobre o contexto das nanotecnologias, das incertezas quanto aos riscos que produzem e dos limites para a exploração nanotecnológica, em um cenário legislativo atual, de ausência de marcos regulatórios específicos, levando à conclusão de que, não se pode "apostar bens jurídicos" futuros e comprometer a manutenção da humanidade, ainda que não se tenha marco regulatório específico.

Para isto serve a dignidade humana como freio do avanço tecnológico a qualquer preço, impondo-se o reconhecimento da necessidade da gestão adequada dos riscos que as nanotecnologias contem. Logo é correto concluir que há pontos convergentes, dentro do cenário das nanotecnologias, entre a gestão de riscos baseada no Princípio da Precaução e o novo modelo ético proposto por Hans Jonas, cujo objetivo final é demonstrar que o homem não é um "meio" mas um fim e si, e que não se pode tratar o homem como meio, pelo contrário, assegurar-lhe condições vitais.

Conclui-se então, que a análise do princípio responsabilidade proposto por Hans Jonas é adequada ao atual momento de descobertas em nanoescala e avanços tecnocientíficos, pois entrega ao homem o encargo de incluir em sua tomada de decisões, limites que possibilitem um meio ambiente viável e manutenção da espécie humana, ainda que não se tenha um marco regulatório específico regulando tais explorações tecnológicas e que as organizações estejam avançando na escala nano, movida pelos fatores econômicos que apresentam ser vantajosos. 


\section{REFERÊNCIAS}

BARRETO, Vivente de Paulo. O Fetiche dos Direitos Humanos e outros Temas. Porto Alegre: Livraria do Advogado, 2013.

BORGES, Isabel Cristina Porto; GOMES, Taís Ferraz; ENGELMANN, Wilson. Responsabilidade Civil e Nanotecnologias. São Paulo: Atlas, 2014.

ENGELMANN, Wilson. O "direito de ser informado" sobre as possibilidades e os riscos relacionados às nanotecnologias: o papel do engajamento público no delineamento de um (novo) direito/dever fundamental. In: MENDEs, Gilmar Ferreira, SARLET, Ingo Wolfang, COELHO, Alexandre Zavaglia P. (Org.). Direito, inovação e Tecnologia. São Paulo: Saraiva, 2015.

A nanotecnociência como uma revolução científica> os Direitos Humanos e uma (nova) filosofia na ciência. IN: STRECK, Lênio Luiz; MORAIS, Jose Luis Bolzan de (Organizadores). Constituição, Sistemas Sociais e Hermenêutica, Porto Alegre: Livraria do Advogado Editora; São Leopoldo: UNISINOS, 2010, pp.249-265.

. O princípio da precaução como um direito fundamental: os desafios humanos das pesquisas com o emprego da nanotecnologia. IN: Direitos Fundamentais e Estado: Políticas públicas e práticas democráticas, Tomo I. SOUZA, Ismael Francisco, VIEIRA, Reginaldo de Souza (Organizadores). Crisciúma/SC: UNOESC, 2011.

ENGELMANN, Wilson, FLORES, A.S. 2009. A phrónesis como mediadora ética para os avanços com o emprego das nanotecnologias: em busca de condições para o pleno florescimento humano no mundo nanotech. Revista AJURIS, 36(115): 309-325.

ENGELHARDT JR, H. Tristam. Fundamentos da Bioética. Tradução: José A. Ceschin. São Paulo: Edições Loyola Jesuítas, 1998. Ed: 6ª Edição.

FÉRRIZ, José Luis; FÉRRIZ, Adriana Pereira; RIBEIRO, Luziana Ramalho. A Transmutação do "homo sapiens em homo faber" a ética da responsabilidade em Hans Jones. 2008. Disponível em:

http://www.inicepg.univap.br/cd/INIC_2008/anais/arquivosINIC/INIC0999_01_O.pdf > Acesso em: 11 Ago. 2015.

FERRER, Gabriel Real. La sostenibilidad tecnológica y susdesafios frente al Derecho. Oficina Regional para América Latina y el Caribe del Programa de Naciones Unidas para el Medio Ambiente (PNUMA - UNEP), ROLAC, 2014-43.

HOHENDORFF, Raquel Von; ENGELMANN, Wilson. Nanotecnologias aplicadas aos agroquímicos no Brasil: a gestão dos riscos a partir do diálogo entre fontes do direito. Curitiba: Juruá, 2014. 
JONES, Hans. O princípio responsabilidade: ensaio de uma ética para a civilização tecnológica. Rio de Janeiro: Contraponto: Ed. PUC-Rio, 2006.

LUHMANN, Niklas. Sociología del riesgo. Tradução de Silvia Pappe, Brunhilde Erker, Javier Torres Nafarrate e Luis Felipe Seghura. Guadalajara: Universidad Iberoamericana e Universidad de Guadalajara, 1992.

LENOIR, Timoty. Instituindo a ciência: a produção cultural das disciplinas científicas. São Leopoldo/RS: Unisinos, 2004.

NOGUEIRA, Patricia F.M.; PAINO, Iêda Maria M.; ZUCOLOTTO, Valtencir. Nanosilver: Propriedades, aplicações e impactos na Saúde Pública e Meio Ambiente. Disponível em: <www.visaemdebate.incqs.fiocrus.br>. Acesso em: 18 abr. 2015.

SARLET, Ingo Wolfgang. A Influência dos Direitos Fundamentais no Direito Privado: notas sobre a evolução brasileira. IN: Direito Privado, Constituição e Fronteiras: encontros da associação Luso-alemã de juristas no Brasil. Stefan Grundmann [et al.] São Paulo: Editora Revista dos Tribunais, 2014.

SIQUEIRA, José Eduardo. Ética e tecnociência: uma abordagem segundo o princípio da responsabilidade de Hans Jonas. Londrina: Editora UEL - Universidade Estadual de Londrina, 1998.

SUPIOT, Alain. O Espírito de Filadélfia: a justiça social diante do mercado total. Porto Alegre: Sulina, 2014. 